\title{
Look beyond Catechol-O-Methyltransferase genotype for cathecolamines derangement in migraine: the BioBIM rs4818 and rs4680 polymorphisms study
}

Maria Laura De Marchis ${ }^{1,2+}$, Piero Barbanti ${ }^{3+}$, Raffaele Palmirotta ${ }^{1,4^{*}}$, Gabriella Egeo ${ }^{3}$, Cinzia Aurilia ${ }^{3}$, Luisa Fofi ${ }^{3}$, Serena Piroso ${ }^{3}$, Cristiano lalongo ${ }^{5}$, David Della-Morte ${ }^{1,6}$, Giovanni D'Andrea ${ }^{7}$, Patrizia Ferroni ${ }^{1,4}$ and Fiorella Guadagni ${ }^{1,4}$

\begin{abstract}
Background: The study of COMT gene polymorphisms in migraine could be of particular interest since impaired catecholaminergic neurotransmission, namely chronic dopaminergic and noradrenergic hypofunction, is a peculiar migraine trait. In this study, for the first time, we focused on the role of COMT rs4818 genetic variant, the polymorphism most strongly affecting COMT activity, in migraine. This study was conducted in a cohort of carefully clinical characterized Caucasian migraineurs recruited in a specifically dedicated migraine biobank, providing also a replication study on rs4680 polymorphism.

Findings: Genotyping of rs4680 and rs4818 Catechol-O-Methyltransferase gene polymorphisms was performed on 380 unrelated migraine patients, and 132 healthy subjects matched for age, gender and race-ethnicity, with no clinical evidence or family history of migraine or other neurological diseases. The rs4680 and rs4818 genotypic frequencies did not deviate from those expected for a population in Hardy-Weinberg equilibrium and did not correlate with demographics or clinical migraine features, even when considering migraine subtypes such as dopaminergic migraine, menstrual migraine, and menstrually related migraine.

Conclusions: COMT genotype does not influence migraine susceptibility or phenotype, even considering rs4818 polymorphism and peculiar clinical subtypes. This finding prompts to go over COMT to explain catecholamine derangement in migraine, exploring enzymes involved in catecholamines synthesis and catabolism, such as monoamine-oxidase, dopamine beta-hydroxylase, tyrosine-hydroxylase or tyrosine-decarboxylase, among others.
\end{abstract}

Keywords: COMT; Migraine; Catecholamines; Polymorphism; Disability; SNP; Val 158 Met; Genetics

\section{Introduction}

Non-physiological catecholamine levels play a major role in migraine aetiology [1]. Clinical, pharmacological and biochemical evidence point to a chronic dopaminergic and noradrenergic dysfunction in migraine. Of note, some patients show during the attack symptoms related to dopamine receptor stimulation such as yawning, somnolence and vomiting or to reduced sympathetic function

\footnotetext{
* Correspondence: raffaele.palmirotta@sanraffaele.it

${ }^{\dagger}$ Equal contributors

'Interinstitutional Multidisciplinary Biobank (BioBIM), IRCCS San Raffaele Pisana, Rome, Italy

${ }^{4}$ Telematic University San Raffaele, Rome, Italy

Full list of author information is available at the end of the article
}

such hypotension and, occasionally, syncope $[2,3]$. The deciphering of the biological basis (biotype) of these clinical phenotypes would allow a more precise comprehension of migraine mechanisms and a more tailored migraine treatment.

The Catechol-O-Methyltransferase (COMT) gene [OM IM:+116790], mapping on chromosome 22q11.21, encodes for the major enzyme that degrades catecholamines (dopamine, epinephrine, and norepinephrine). Two COMT transcripts isoforms are produced, leading to the synthesis of a soluble protein (S-COMT), localized in blood and peripheral tissues, and a membrane-bound protein (MB-COMT) concentrated in the brain, mainly in the prefrontal cortex 
[4,5]. The COMT gene contains several SNPs, some of which result in a marked clinical significance. The rs4680 causes a substitution of a Valine (Val: GTG) to Methionine (Met: ATG) at codon 158 for MB-COMT isoform, and at codon 108 for S-COMT isoform [4,5]. These functional amino acid changes lead to a higher dopamine-degrading activity (H: high) for the Val158 variant and to a lower thermostability and enzymatic activity (L: lower) for the Met158 variant [6-8]. COMT activity is 3 to 4 times higher in Val homozygous compared to Met homozygous genotype carriers [9]. The rs4680 has been related to human pain perception, cognitive phenotypes, psychiatric disorders and variations in brain activation and structure $[4,10]$. The synonymous polymorphism rs 4818 causes a C/G substitution at codon 86 of S-COMT and 136 of MB-COMT, corresponding to a Leucine residue. This genetic variant is related to a haploblock comprising rs6269 (A/G), rs4633 $(\mathrm{C} / \mathrm{T})$, rs4818 (G/C) and rs4680 (A/G), which strongly affects the efficiency of protein synthesis based on the specific haplotype, leading to a huge variation in enzyme activity [11]. Three major haplotypes influencing COMT activity and pain sensitivity were identified: a "low pain sensitivity" haplotype (G-C-G-G), characterized by a 11.4 times higher COMT activity compared with the "high pain sensitivity" haplotype (A-C-C-G), and an "average pain sensitivity" haplotype (A-T-C-A), with intermediate COMT activity values [11]. Variability at the rs4818 has been correlated to cognitive functions: the $\mathrm{G}$ allele, corresponding to high COMT activity levels and low tonic prefrontal cortex dopamine signalling, has been associated to a less efficient planning and problem solving ability, lower prepulse inhibition levels and working memory performance [12].

The study of COMT polymorphism in migraine has been mainly focused on the rs4680 polymorphism (Table 1) however providing inconclusive results, mainly due to small sampling and poor patients' clinical characterization [13-21]. Surprisingly, the rs4818 polymorphism, despite its strong influence on COMT activity, has still not been investigated. We also noticed that the combined assessment of rs4680 and rs4818 was sufficient to provide a high degree of informativeness relatively to the overmentioned haplotypes [11].

Therefore, in the present study we sought to study the relationship between COMT rs4818 polymorphism and migraine in a detailed clinical migraine Caucasian population, whose biological samples were stored in a specifically dedicated migraine biobank (Interinstitutional Multidisciplinary BioBank-BioBIM), providing also a replication study on rs4680 polymorphism [22].

\section{Findings \\ Populations}

Three hundred-eighty Mediterranean Caucasian unrelated individuals affected by migraine without aura (MwoA, $\mathrm{n}=$
189; $\mathrm{M} / \mathrm{F}=34 / 155$; mean age $40.3 \pm 11.9$ yrs), migraine with aura (MwA, $\mathrm{n}=65 ; \mathrm{M} / \mathrm{F}=16 / 49$; mean age $39.4 \pm$ 12.6 yrs) or chronic migraine ( $\mathrm{CM}, \mathrm{n}=126 ; \mathrm{M} / \mathrm{F}=14 / 112$; mean age $47.5 \pm 13.3 \mathrm{yrs}$ ) were consecutively recruited at our Headache and Pain Unit (IRCCS San Raffaele Pisana, Rome) from 01/01/2012 to 31/12/2013 [23,24].

As controls we enrolled 132 healthy subjects $(\mathrm{M} / \mathrm{F}=57 /$ 75 ; mean age $38.3 \pm 12.4$ yrs) with no clinical evidence or family history of migraine or other neurological diseases, matched for age, gender and race-ethnicity. Informative and consent forms by the institutional Ethics Committee of San Raffaele Scientific Institute were provided to both groups, together with the permission to obtain blood samples for research purposes. The protocol was approved by the institutional review board at San Raffaele Scientific Institute and have therefore been performed in accordance with the ethical standards laid down in the 1964 Declaration of Helsinki. All subjects gave their informed consent prior to their inclusion in the study.

\section{Assessment of migraineurs' clinical characteristics}

All migraineurs underwent a complete physical, neurological and fundoscopic examination. Detailed information on patients' socio-demographic characteristics, lifestyle, migraine features, concomitant diseases and medications were gathered with face-to-face interviews using a semistructured questionnaire. Migraine features included disease duration, family history of migraine, migraine type (episodic, chronic, MwoA, MwA, pure menstrual, menstrually-related [24]), frequency and duration of attacks, location, quality and intensity of pain, presence of dopaminergic symptoms (assessed by asking: "Before or during the attack do you present yawning, vomiting or somnolence?), presence of unilateral cranial parasympathetic symptoms, response to triptans (rated as absent/ poor, fair, good/excellent), duration of chronic migraine, preventive and acute treatment, presence and duration of medication overuse.

\section{DNA extraction and genotyping}

All biological samples were stored at the BioBIM of IRCCS San Raffaele Pisana following the biobanking Standard Operative Procedures (SOPs) [25]. DNA was isolated from ethylenediaminetetraacetate (EDTA) anticoagulated whole blood using MagNApure LC instrument and the MagNApure LC total DNA isolation kit I (Roche Diagnostics $\mathrm{GmbH}$, Mannheim, Germany) according to the manufacturer's instructions.

COMT polymorphisms rs4818 and rs4680 were determined by a 261-bp standard PCR amplification in a GeneAmp PCR System 9700 (Applied Biosystems, Carlsbad, CA, USA) using HotStarTaq Master Mix (HotStarTaq Master Mix Kit, QIAGEN, Inc., Chatsworth, CA, USA) on the basis of the COMT Ensembl sequence [Ensembl: 
Table 1 Reported association studies between COMT polymorphisms and migraine (pts: patients)

\begin{tabular}{|c|c|c|c|c|c|c|c|}
\hline Patients (M/F) & Headache subtype & $\begin{array}{l}\text { Healthy } \\
\text { controls (M/F) }\end{array}$ & Mean age (years) & $\begin{array}{l}\text { Country, } \\
\text { Race-Ethnicity }\end{array}$ & Polymorphism & Comment & Reference \\
\hline \multirow[t]{3}{*}{$62(11 / 51)$} & -Migraine with aura (33) & & -Patients (32 \pm 5.2$)$ & & & & \\
\hline & -Migraine without aura (29) & $64(14 / 50)$ & -Controls $(30.7 \pm 6.3)$ & Turkey, Asian & rs4680 & $\begin{array}{l}\text { allele and migraine }(P=0.013) \\
\text { and with family history of } \\
\text { migraine }(P=0.003) \text {. }\end{array}$ & Emin Erdal et al., 2001 [13] \\
\hline & -Migraine (305) & & -Patients (46.8) & & & No association with migraine. & \\
\hline $982(346 / 636)$ & -Non-migrainous headache (677) & 1468 & -Controls (55.5) & Norway, Caucasian & rs4680 & $\begin{array}{l}\text { Association of the } \mathrm{Val} / \mathrm{Nal} \\
\text { genotype with non-migrainous } \\
\text { headache in female patients } \\
(P=0.04) \text {. }\end{array}$ & Hagen et al., 2006 [14] \\
\hline \multirow{2}{*}{219} & -Migraine with aura (92) & 144 & - & Germany Caucasian & rs 4680 & No association & Mössner et al 2006 [15] \\
\hline & -Migraine without aura (127) & 144 & - & Gemany Caucasidn! & 154000 & TNO dssociationt. & 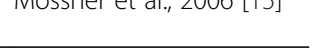 \\
\hline \multirow[t]{3}{*}{204} & -Chronic daily headache with & & -Patients (range 23-81) & & & & \\
\hline & arug abuse (IU3) & 117 & & Italy Caucasian & rs4680 & No association. & Cevoli et al., 2006 [16] \\
\hline & $\begin{array}{l}\text {-Migraine without aura without } \\
\text { drug abuse (101) }\end{array}$ & & -Controls (over 40) & & & & \\
\hline 97 & Migraine without aura (97) & 94 & - & Korea Asian & rs4680 & $\begin{array}{l}\text { Met allele associated with a } \\
\text { higher pain intensity of } \\
\text { headache }(P=0.001) \text { and } \\
\text { nausea/vomiting occurring } \\
(P=0.026) \text {. }\end{array}$ & Park et al., 2007 [17] \\
\hline \multirow[t]{6}{*}{263} & & & & & rs2020917 & & \\
\hline & Migraine without aura (55.9\%) & 274 & -Patients (37 \pm 16$)$ & & rs933271 & & \\
\hline & & & & & rs1544325 & & \\
\hline & & & & & rs740603 & & \\
\hline & & & & & rs740601 & & \\
\hline & & & & Spain Caucasian & rs4680 & No association. & Corominas et al., 2009 [18] \\
\hline \multirow{4}{*}{259} & Miaraine without a ara (61 40) & & Controls $(55+18)$ & & rs4646316 & & \\
\hline & Mıgraine without aura (61.4\%) & 281 & -Controls (55 \pm 18$)$ & & rs174696 & & \\
\hline & & & & & rs165774 & & \\
\hline & & & & & rs9332377 & & \\
\hline \multirow{7}{*}{270} & & & & & rs4485648 & & \\
\hline & Migraine with aura (270) & & & & rs933271 & & \\
\hline & & & & & rs740603 & & \\
\hline & & 272 & - & Germany Caucasian & rs4680 & No association & Todt et al 2009 [19] \\
\hline & & & & & rs4646316 & the associationt. & \\
\hline & & & & & rs165774 & & \\
\hline & & & & & rs5993889 & & \\
\hline
\end{tabular}


Table 1 Reported association studies between COMT polymorphisms and migraine (pts: patients) (Continued)

\begin{tabular}{|c|c|c|c|c|c|c|c|}
\hline \multirow[t]{3}{*}{$1132(240 / 892)$} & \multirow{2}{*}{$\begin{array}{l}\text {-Females with hormonally } \\
\text { modulated migraine (464) }\end{array}$} & \multirow{3}{*}{$608(258 / 350)$} & \multicolumn{3}{|l|}{ Patients (range 18-50) } & \multirow{3}{*}{$\begin{array}{l}\text { Significant association with } \\
\text { migraine }(P=0.001) \text { and } \\
\text { hormonally modulated migraine } \\
(P=0.03)\end{array}$} & \multirow{3}{*}{ Sullivan et al., 2013 [20] } \\
\hline & & & Controls (range 19-50) & USA, White race $\sim 90 \%$ & rs4680 & & \\
\hline & $\begin{array}{l}\text {-Females with nonhormonally } \\
\text { modulated migraine ( } 364)\end{array}$ & & & & & & \\
\hline \multirow{3}{*}{$198(40 / 158)$} & $\begin{array}{l}\text {-1st cohort: Migraine without } \\
\text { aura (75) }\end{array}$ & & & & & \multirow{3}{*}{$\begin{array}{l}\text { Significant association between } \\
\text { the Val/Nal genotype and } \\
\text { response to triptans. }\end{array}$} & \multirow{3}{*}{ Cargnin et al., 2013 [21] } \\
\hline & $\begin{array}{l}\text {-2nd cohort: Migraine without } \\
\text { aura (111) }\end{array}$ & - & - & Italy Caucasian & rs4680 & & \\
\hline & Migraine with aura (12) & & & & & & \\
\hline
\end{tabular}


ENSG00000093010], using the following primers: F5' $-\mathrm{T}$ GTGCTCACCTCTCCTCC-3' and R5' - CAGGTCTGAC AACGGGTC-3'.

All Sanger sequencing analyses were carried out in order to exclude pre-analytical and analytical errors on both strands using Big Dye Terminator v3.1 Cycle Sequencing kit (Applied Biosystems), run on an ABI 3130 Genetic Analyzer (Applied Biosystems) and repeated on PCR products obtained from new nucleic acid extractions.

\section{Statistics}

Data are presented as mean and standard deviation (SD). The allelic frequencies were estimated by gene counting, and the genotypes were scored. The observed numbers of COMT genotypes were compared with that expected for a population in Hardy-Weinberg equilibrium. The significance of the differences of observed alleles, genotypes and haplotypes between groups as well as analysis of multiple inheritance models (codominant, dominant, recessive, overdominant, and log-additive) were also tested using SNPStats (http://bioinfo.iconcologia.net/ snpstats/start.htm).

Association of nominal variables was assessed by chi square test of Fisher-Freeman-Halton (FFH) test where needed. For continuous variables, association with a factor was assessed by General Linear Model (GLM) corrected for sex and familiarity for migraine with Tukey's HSD (Honest Significant Difference) post hoc test. All calculations were made by SPPS 20 (IBM Corp, Armonk, NY), except for power analysis, done by G*Power 3.1.3 free software (Heinrich Heine Universitat, Dusseldorf, Ge). The statistical power reached for GLM for fixed main effects was of $94.5 \%$ for an effect size $\mathrm{f} 0.2$ and a type I error probability of $5 \%$.

\section{Study results}

Our study population consists of 380 Caucasian individuals affected by migraine (MwoA $=49,7 \%, \mathrm{MwA}=17,1 \%$, $\mathrm{CM}=33,2 \%)$, and 132 healthy subjects. Table 2 reports genotypes and allele frequencies of the rs4818 and rs4680 polymorphisms. No significant differences were found between these frequencies and those predicted by the HardyWeinberg equilibrium. Haplotype analysis revealed no linkage disequilibrium between the analyzed polymorphisms. We also tested differences of genotypes between groups by analysis of multiple inheritance models but they were not statistically significant (Table 3 ).

We found no association between rs4818 and rs4680 polymorphisms and migraine susceptibility $(\mathrm{P}=0.336$, and $\mathrm{P}=0.577$, respectively), migraine type (MwoA, MwA, CM) $(P=0.620, P=0.858)$, gender $(P=0.081, P=0.220)$, mean age of onset $(\mathrm{P}=0.821, \mathrm{P}=0.526)$, laterality of attacks $(\mathrm{P}=$ 0.917, $\mathrm{P}=0.954)$, dopaminergic symptoms $(\mathrm{P}=0.615, \mathrm{P}=$ 0.089), unilateral cranial autonomic symptoms $(P=0.233$, $\mathrm{P}=0.680)$, migraine prophylaxis $(\mathrm{P}=0.489, \mathrm{P}=0.900)$, analgesics overuse $(P=0.647, P=0.399)$, type of analgesic overused $(\mathrm{P}=0.800, \mathrm{P}=0368)$ or other clinical and sociodemographic characteristics (data not shown). No association was found between COMT rs4818 and rs4680 genotypes and pharmacological treatment response, particularly in the 218 patients treated with triptans $(\mathrm{P}=0.558$, $\mathrm{P}=0.956$ ). Furthermore, no correlation was found between rs4818 and rs4680 polymorphisms and pure menstrual or menstrual related migraine $(\mathrm{n}=85 \mathrm{pts})(\mathrm{P}>0.05)$.

\section{Discussion}

The study of COMT gene polymorphisms in migraine is intriguing since an impaired catecholaminergic neurotransmission, namely a chronic dopaminergic and noradrenergic

Table 2 Distributions of genotype and allele frequencies of COMT polymorphism rs4680 and rs4818 observed in patients and controls

\begin{tabular}{|c|c|c|c|c|c|c|c|}
\hline & \multirow[t]{2}{*}{$\mathbf{N}$} & \multicolumn{3}{|c|}{ rs4680 genotypes (\%) } & \multicolumn{2}{|c|}{ rs4680 alleles (\%) } & \multirow[t]{2}{*}{ HW (P value) } \\
\hline & & AA (Met/Met) & AG (Met/Val) & GG (Val/Val) & $A$ & G & \\
\hline Controls & 132 & $23(17.4)$ & $65(49.2)$ & $44(33.3)$ & $111(42.0)$ & $153(58.0)$ & 0,90 \\
\hline All patients with migraine & 380 & $78(20.5)$ & $192(50.5)$ & $110(28.9)$ & $348(45.7)$ & $412(54.3)$ & 0,73 \\
\hline Migraine with Aura & 65 & $15(23.1)$ & $30(46.1)$ & $20(30.8)$ & $60(46.2)$ & $70(53.8)$ & 0,56 \\
\hline Migraine w/out Aura & 189 & $41(21.7)$ & $96(50.8)$ & $52(27.5)$ & $178(47.1)$ & $200(52.9)$ & 0,79 \\
\hline \multirow[t]{3}{*}{ Chronic Migraine } & 126 & $22(17.5)$ & $66(52.4)$ & $38(30.1)$ & $110(43.7)$ & $142(56.3)$ & 0,47 \\
\hline & $\mathbf{N}$ & \multicolumn{3}{|c|}{ rs4818 genotypes (\%) } & \multicolumn{2}{|c|}{ rs4818 alleles (\%) } & HW (P value) \\
\hline & & CC (Leu/Leu) & CG (Leu/Leu) & GG (Leu/Leu) & C & G & \\
\hline Controls & 132 & $30(22.7)$ & $76(57.6)$ & $26(19.7)$ & $136(51.5)$ & $128(48.5)$ & 0,08 \\
\hline All patients with migraine & 380 & $111(29.3)$ & $197(51.8)$ & $72(18.9)$ & $419(55.1)$ & $341(44.9)$ & 0,35 \\
\hline Migraine with Aura & 65 & $21(32.3)$ & $30(46.2)$ & $14(21.5)$ & $72(55.4)$ & $58(44.6)$ & 0,59 \\
\hline Migraine w/out Aura & 189 & $50(26.5)$ & $104(55.0)$ & $35(18.5)$ & $204(54.0)$ & $174(46.0)$ & 0,14 \\
\hline Chronic Migraine & 126 & $40(31,7)$ & $63(50.0)$ & $23(18.3)$ & $143(56.7)$ & $109(43.3)$ & 0,84 \\
\hline
\end{tabular}

Values are given as no. (\%). HW: Hardy-Weinberg equilibrium. 
Table 3 Differences of genotypes distributions between Migraine groups and multiple inheritance models using the WEB Tool SNPStats (http://bioinfo.iconcologia.net/snpstats/start.htm)

\begin{tabular}{|c|c|c|c|c|c|c|c|c|c|}
\hline \multicolumn{4}{|c|}{ Migraine with Aura } & \multicolumn{3}{|c|}{ Migraine w/out Aura } & \multicolumn{3}{|l|}{ Chronic Migraine } \\
\hline Model & rs4680 genotypes & OR $(95 \% \mathrm{Cl})$ & P-value & rs4680 genotypes & OR (95\% Cl) & P-value & rs4680 genotypes & OR $(95 \% \mathrm{Cl})$ & P-value \\
\hline \multirow[t]{3}{*}{ Codominant } & $\mathrm{G} / \mathrm{G}$ & 1.00 & 0.65 & $\mathrm{G} / \mathrm{G}$ & 1.00 & 0.44 & $\mathrm{G} / \mathrm{G}$ & 1.00 & 0.87 \\
\hline & $A / G$ & $1.02(0.51-2.01)$ & & $A / G$ & $1.25(0.75-2.08)$ & & $A / G$ & $1.16(0.67-2.01)$ & \\
\hline & $\mathrm{A} / \mathrm{A}$ & $1.43(0.62-3.32)$ & & $\mathrm{A} / \mathrm{A}$ & $1.51(0.79-2.89)$ & & $\mathrm{A} / \mathrm{A}$ & $1.11(0.53-2.29)$ & \\
\hline \multirow[t]{2}{*}{ Dominant } & $\mathrm{G} / \mathrm{G}$ & 1.00 & 0.72 & $\mathrm{G} / \mathrm{G}$ & 1.00 & 0.26 & $\mathrm{G} / \mathrm{G}$ & 1.00 & 0.61 \\
\hline & $\mathrm{A} / \mathrm{G}-\mathrm{A} / \mathrm{A}$ & $1.12(0.59-2.13)$ & & $\mathrm{A} / \mathrm{G}-\mathrm{A} / \mathrm{A}$ & $1.32(0.81-2.13)$ & & $\mathrm{A} / \mathrm{G}-\mathrm{A} / \mathrm{A}$ & $1.14(0.68-1.94)$ & \\
\hline \multirow[t]{2}{*}{ Recessive } & $\mathrm{G} / \mathrm{G}-\mathrm{A} / \mathrm{G}$ & 1.00 & 0.35 & $\mathrm{G} / \mathrm{G}-\mathrm{A} / \mathrm{G}$ & 1.00 & 0.34 & $\mathrm{G} / \mathrm{G}-\mathrm{A} / \mathrm{G}$ & 1.00 & 0.97 \\
\hline & $\mathrm{A} / \mathrm{A}$ & $1.42(0.68-2.95)$ & & $\mathrm{A} / \mathrm{A}$ & $1.31(0.74-2.32)$ & & $\mathrm{A} / \mathrm{A}$ & $1.01(0.53-1.93)$ & \\
\hline \multirow[t]{2}{*}{ Overdominant } & $\mathrm{G} / \mathrm{G}-\mathrm{A} / \mathrm{A}$ & 1.00 & 0.68 & $\mathrm{G} / \mathrm{G}-\mathrm{A} / \mathrm{A}$ & 1.00 & 0.78 & G/G-A/A & 1.00 & 0.66 \\
\hline & $A / G$ & $0.88(0.49-1.60)$ & & $A / G$ & $1.06(0.68-1.66)$ & & $A / G$ & $1.12(0.68-1.82)$ & \\
\hline Log-additive & --- & $1.18(0.77-1.79)$ & 0.44 & --- & $1.23(0.89-1.70)$ & 0.2 & --- & $1.07(0.75-1.52)$ & 0.72 \\
\hline Model & rs4818 genotypes & OR $(95 \% \mathrm{Cl})$ & P-value & rs4818 genotypes & OR $(95 \% \mathrm{Cl})$ & P-value & rs4818 genotypes & OR $(95 \% \mathrm{Cl})$ & P-value \\
\hline \multirow[t]{3}{*}{ Codominant } & $\mathrm{C} / \mathrm{C}$ & 1.00 & 0.27 & $\mathrm{C} / \mathrm{C}$ & 1.00 & 0.75 & $\mathrm{C} / \mathrm{C}$ & 1.00 & 0.24 \\
\hline & $C / G$ & $0.56(0.28-1.14)$ & & $C / G$ & $0.82(0.48-1.41)$ & & $C / G$ & $0.61(0.34-1.09)$ & \\
\hline & $\mathrm{G} / \mathrm{G}$ & $0.77(0.33-1.81)$ & & $\mathrm{G} / \mathrm{G}$ & $0.81(0.41-1.59)$ & & $\mathrm{G} / \mathrm{G}$ & $0.66(0.32-1.38)$ & \\
\hline \multirow[t]{2}{*}{ Dominant } & $\mathrm{C} / \mathrm{C}$ & 1.00 & 0.15 & $\mathrm{C} / \mathrm{C}$ & 1.00 & 0.45 & $\mathrm{C} / \mathrm{C}$ & 1.00 & 0.095 \\
\hline & $\mathrm{C} / \mathrm{G}-\mathrm{G} / \mathrm{G}$ & $0.62(0.32-1.19)$ & & $\mathrm{C} / \mathrm{G}-\mathrm{G} / \mathrm{G}$ & $0.82(0.49-1.38)$ & & $\mathrm{C} / \mathrm{G}-\mathrm{G} / \mathrm{G}$ & $0.63(0.36-1.09)$ & \\
\hline \multirow[t]{2}{*}{ Recessive } & $\mathrm{C} / \mathrm{C}-\mathrm{C} / \mathrm{G}$ & 1.00 & 0.76 & $\mathrm{C} / \mathrm{C}-\mathrm{C} / \mathrm{G}$ & 1.00 & 0.79 & $\mathrm{C} / \mathrm{C}-\mathrm{C} / \mathrm{G}$ & 1.00 & 0.79 \\
\hline & $\mathrm{G} / \mathrm{G}$ & $1.12(0.54-2.32)$ & & $\mathrm{G} / \mathrm{G}$ & $0.93(0.53-1.63)$ & & $\mathrm{G} / \mathrm{G}$ & $0.92(0.49-1.71)$ & \\
\hline \multirow[t]{2}{*}{ Overdominant } & C/C-G/G & 1.00 & 0.13 & $\mathrm{C} / \mathrm{C}-\mathrm{G} / \mathrm{G}$ & 1.00 & 0.65 & C/C-G/G & 1.00 & 0.2 \\
\hline & $C / G$ & $0.63(0.35-1.15)$ & & $C / G$ & $0.90(0.58-1.41)$ & & $C / G$ & $0.73(0.44-1.19)$ & \\
\hline Log-additive & --- & $0.84(0.54-1.31)$ & 0.45 & --- & $0.89(0.64-1.25)$ & 0.51 & --- & $0.79(0.55-1.14)$ & 0.21 \\
\hline
\end{tabular}


hypofunction, is a peculiar migraine trait [1-3]. This is the first COMT study performed on a cohort of carefully clinical characterized Caucasian migraineurs recruited in a specifically dedicated migraine biobank [23] and focused on the role of rs 4818 variant, the polymorphism most strongly affecting COMT activity. In our association analysis the control group was chosen balance the average size of the three pathological groups considered. Therefore, power analysis showed that such a setup sufficed the requirement of at least $90 \%$ sensitivity respect to a pretty small effect size (almost comparable to an Odds Ratio of 2.066). In our opinion the power we reached ensured that the negative findings we reported were due to a lack of significant association, rather than to a misrecognized negligible effect.

The main finding of the present study is that COMT rs4818 polymorphism does not influence the susceptibility or clinical phenotype of MwoA, MwA or CM, even when considering migraine patients subsets, such as those characterized before or during the attack by symptoms due to pre- or post-synaptic dopamine receptor activation, such as yawning, vomiting and hypotension (dopaminergic migraineurs) [3] or those with pure menstrual or menstrually related migraine (hormonally modulated migraine, HMM [20]). Moreover, our replication study supports previous results excluding any correlation between COMT rs4680 polymorphism and migraine in Caucasians patients [14-16,18,19], in contrast with a putative correlation found only in Korean and Turkish population [13,17]. Such discrepancies may be related either to smaller sample size or to differences in variant frequency related to race/ethnicity of different population studies.

Our results do not confirm the hypothesis that COMT rs4680 genotype influences the clinical response to triptans as previously suggested [21], albeit our study was performed on a comparable patients sample (218 vs 198 pts). Possible explanations include the fact that our study was not selectively focused on triptans clinical response and considered different criteria to assess triptan responsivity. Finally we did not find significant association between the rs4680 variant and HMM as previously reported by Sullivan et al. [20] probably due to the unequal proportion of women with this subtype of migraine in the present study.

Our study, reasonably, cuts out a direct involvement of COMT gene polymorphisms in migraine even when considering the rs 4818 polymorphism. This is not necessarily in contrast with the catecholaminergic derangement widely described in migraine [1]. We suggest that probably other catecholamine catabolic or biosynthetic enzymes, such as monoamine-oxidase, dopamine beta-hydroxylase, tyrosine-hydroxylase or tyrosine-decarboxylase are involved in the dopaminergic and noradrenergic impairment characterizing migraine sufferers [1-3].
Catecholamines originate from tyrosine metabolism through a hydroxylase-related pathway. In migraineurs, a reduction in mitochondrial energy would favour a metabolic shift directing tyrosine metabolism toward decarboxylation pathway instead of the hydroxylation one, leading to reduced catecholamines production and high trace amine levels in the pain matrix, and, ultimately, to the trigemino-vascular system activation, triggering the attack [1].

We acknowledge that potential recall bias and the recruitment in a tertiary-referral center are limitations of our study. Strengths include the use of data based on a specifically dedicated migraine biobank and a careful clinical and demographic characterization of all patients studied using with face-to-face interviews.

\section{Conclusions}

In conclusion, COMT genotype does not influence migraine susceptibility or phenotype, even when considering peculiar clinical subtypes (dopaminergic migraine, HMM). This finding coupled with the well established catecholaminergic imbalance characterizing migraine biotypes prompts to a thorough investigation of other enzymes involved in catecholamines synthesis and catabolism.

\section{Abbreviations}

COMT: Catechol-O-Methyltransferase; S-COMT: Soluble Catechol-OMethyltransferase; MB-COMT: Membrane bound Catechol-O-

Methyltransferase; Val: Valine; Met: Metionine; SNP: Single nucleotide polymorphism; BioBIM: Interinstitutional Multidisciplinary BioBank;

SOPs: Standard Operating Procedures; ICHD: International classification of headache disorder; MwoA: Migraine without aura; MwA: Migraine with aura; CM: Chronic migraine; UAs: Unilateral cranial autonomic symptoms; SD: Standard deviation; GLM: General linear model; HSD: Honest significant difference; FFH: Fisher-Freeman-Halton; HMM: Hormonally modulated migraine; NHMM: Non-hormonally modulated migraine; Pts: Patients.

\section{Competing interests}

The authors declare that they have no competing interests.

\section{Authors' contributions}

MLDM carried out the molecular genetic studies, participated in the sequence alignment and drafted the manuscript. PB and RP conceived of the study, participated in its design and coordination and helped to draft the manuscript. GE, CA, LF and SE participated in patients recruitment. CI collected and interpreted the data and performed statistical analysis. DDM, GDA, PF and FG conceptualized and designed the study, revised the manuscript and approved the final manuscript as submitted. All authors read and approved the final manuscript.

\section{Acknowledgements}

This study was partially supported by the European Social Fund, under the Italian Ministry of Education, University and Research PONO3PE_00146_ 1/10 BIBIOFAR (CUP B88F12000730005) to F.G and by Grant MERIT RBNE08NKH7 to San Raffaele Foundation Ceglie Messapica (http:// www.fondazionesanraffaele.com/). We thank A.R.B.Onlus for supporting the publication of this paper.

\section{Author details}

${ }^{1}$ Interinstitutional Multidisciplinary Biobank (BioBIM), IRCCS San Raffaele Pisana, Rome, Italy. 'Department of Cardiovascular, Respiratory, Nephrologic, Geriatric and Anesthesiological Sciences, Sapienza University, Rome, Italy. ${ }^{3}$ Headache and Pain Unit, Department of Neurological, Motor and Sensorial Sciences, IRCCS San Raffaele Pisana, Rome, Italy. ${ }^{4}$ Telematic University San 
Raffaele, Rome, Italy. ${ }^{5}$ Department of Internal Medicine, Tor Vergata University, Rome, Italy. ${ }^{6}$ Department of Systems Medicine, Tor Vergata University, Rome, Italy. ${ }^{7}$ Research \& Innovation (R\&l) srl, Padua, Italy.

Received: 4 March 2015 Accepted: 16 April 2015

Published online: 30 April 2015

\section{References}

1. D'Andrea G, D'Arrigo A, Dalle Carbonare M, Leon A (2012) Pathogenesis of migraine: role of neuromodulators. Headache 52(7):1155-1163

2. Peroutka SJ (2004) Migraine: a chronic sympathetic nervous system disorder. Headache 44(1):53-64

3. Barbanti P, Fofi L, Aurilia C, Egeo G (2013) Dopaminergic symptoms in migraine. Neurol Sci 34(Suppl 1):S67-70

4. Tammimäki A, Männistö PT (2012) Catechol-O-methyltransferase gene polymorphism and chronic human pain: a systematic review and meta-analysis. Pharmacogenet Genomics 22(9):673-691

5. Chen J, Song J, Yuan P, Tian Q, Ji Y, Ren-Patterson R, Liu G, Sei Y, Weinberger DR (2011) Orientation and cellular distribution of membrane-bound catechol-O-methyltransferase in cortical neurons: implications for drug development. J Biol Chem 286(40):34752-34760

6. Witte AV, Flöel A (2012) Effects of COMT polymorphisms on brain function and behavior in health and disease. Brain Res Bull 88(5):418-428

7. Tunbridge EM (2010) The catechol-O-methyltransferase gene: its regulation and polymorphisms. Int Rev Neurobiol 95:7-27

8. Hernaus D, Collip D, Lataster J, Ceccarini J, Kenis G, Booij L, Pruessner J, Van Laere K, van Winkel R, van Os J, Myin-Germeys I (2013) COMT Val158Met genotype selectively alters prefrontal [18 F] fallypride displacement and subjective feelings of stress in response to a psychosocial stress challenge. PLoS One 8(6), e65662

9. Lotta T, Vidgren J, Tilgmann C, Ulmanen I, Melén K, Julkunen I, Taskinen J (1995) Kinetics of human soluble and membrane-bound catechol O-methyltransferase: a revised mechanism and description of the thermolabile variant of the enzyme. Biochemistry 34(13):4202-4210

10. Ira E, Zanoni M, Ruggeri M, Dazzan P, Tosato S (2013) COMT, neuropsychological function and brain structure in schizophrenia: a systematic review and neurobiological interpretation. J Psychiatry Neurosci 38(6):366-380

11. Diatchenko L, Slade GD, Nackley AG, Bhalang K, Sigurdsson A, Belfer I, Goldman D, Xu K, Shabalina SA, Shagin D, Max MB, Makarov SS, Maixner W (2005) Genetic basis for individual variations in pain perception and the development of a chronic pain condition. Hum Mol Genet 14(1):135-143

12. Roussos P, Giakoumaki SG, Pavlakis S, Bitsios P (2008) Planning, decision-making and the COMT rs 4818 polymorphism in healthy males. Neuropsychologia 46(2):757-763

13. Emin Erdal M, Herken H, Yilmaz M, Bayazit YA (2001) Significance of the catechol-O-methyltransferase gene polymorphism in migraine. Brain Res Mol Brain Res 94(1-2):193-196

14. Hagen K, Pettersen E, Stovner LJ, Skorpen F, Zwart JA (2006) The association between headache and Val158Met polymorphism in the catechol-Omethyltransferase gene: the HUNT Study. J Headache Pain 7(2):70-74

15. Mössner R, Freitag CM, Marziniak M, Moser D, Sommer C, Meyer J (2006) The functional Val158Met variant of the COMT gene is not associated with migraine with or without aura. J Headache Pain 7(3):165-166

16. Cevoli S, Mochi M, Scapoli C, Marzocchi N, Pierangeli G, Pini LA, Cortelli P, Montagna P (2006) A genetic association study of dopamine metabolismrelated genes and chronic headache with drug abuse. Eur J Neurol 13(9):1009-1013

17. Park JW, Lee KS, Kim JS, Kim YI, Shin HE (2007) Genetic contribution of catechol-O-methyltransferase polymorphism in patients with migraine without aura. J Clin Neurol 3(1):24-30

18. Corominas R, Ribases M, Camiña M, Cuenca-León E, Pardo J, Boronat S, Sobrido MJ, Cormand B, Macaya A (2009) Two-stage case-control association study of dopamine-related genes and migraine. BMC Med Genet 10:95

19. Todt U, Netzer C, Toliat M, Heinze A, Goebel I, Nürnberg P, Göbel H, Freudenberg J, Kubisch C (2009) New genetic evidence for involvement of the dopamine system in migraine with aura. Hum Genet 125(3):265-279

20. Sullivan AK, Atkinson EJ, Cutrer FM (2013) Hormonally modulated migraine is associated with single-nucleotide polymorphisms within genes involved in dopamine metabolism. Open J Genet 3:38-45
21. Cargnin S, Magnani F, Viana M, Tassorelli C, Mittino D, Cantello R, Sances G, Nappi G, Canonico PL, Genazzani AA, Raffaeli W, Terrazzino S (2013) An opposite-direction modulation of the COMT Val158Met polymorphism on the clinical response to intrathecal morphine and triptans. J Pain 14(10):1097-1106

22. NCI-NHGRI Working Group on Replication in Association Studies, Chanock SJ, Manolio T, Boehnke M, Boerwinkle E, Hunter DJ, Thomas G, Hirschhorn JN, Abecasis G, Altshuler D, Bailey-Wilson JE, Brooks LD, Cardon LR, Daly M, Donnelly P, Fraumeni JF Jr, Freimer NB, Gerhard DS, Gunter C, Guttmacher AE, Guyer MS, Harris EL, Hoh J, Hoover R, Kong CA, Merikangas KR, Morton CC, Palmer LJ, Phimister EG, Rice JP, Roberts J, Rotimi C, Tucker MA, Vogan KJ, Wacholder S, Wijsman EM, Winn DM, Collins FS (2007) Replicating genotype-phenotype associations. Nature 447(7145):655-660

23. Palmirotta R, Barbanti P, Ludovici G, Egeo G, Aurilia C, Fofi L, De Marchis ML, Spila A, Ferroni P, Della-Morte D, Guadagni F (2013) Establishment of a biorepository for migraine research: the experience of Interinstitutional Multidisciplinary BioBank (BioBIM). Neurol Sci 34(9):1659-1663

24. Headache Classification Committee of the International Headache Society (IHS) (2013) The international classification of headache disorders, 3rd edition (beta version). Cephalalgia 33(9):629-808

25. Palmirotta R, Ludovici G, De Marchis ML, Savonarola A, Leone B, Spila A, De Angelis F, Della Morte D, Ferroni P, Guadagni F (2011) Pre-analytical procedures for DNA studies: the experience of the interinstitutional multidisciplinary BioBank (BioBIM). Biopreserv Biobank 9:35-45

\section{Submit your manuscript to a SpringerOpen ${ }^{\circ}$ journal and benefit from:}

- Convenient online submission

- Rigorous peer review

- Immediate publication on acceptance

- Open access: articles freely available online

- High visibility within the field

- Retaining the copyright to your article

Submit your next manuscript at $\boldsymbol{\wedge}$ springeropen.com 